\title{
ABILITY OF THE INFORMATION-LEADER TO CREATE TOPICS OF CONVERSATION AND PURCHASE DECISION-MAKING
}

\author{
Takashi Teramoto, Meisei University, Japan
}

\begin{abstract}
In recent years, it appears that the process in which the consumer obtains information on a new product, recognizes the product and then puts it in his or her consideration set as a candidate for purchase is changing along with the popularity of Twitter, Facebook and other SNSs. The new flow is for the consumer to identify a given product as a candidate for purchase not only through recognition but also after talking about it with acquaintances and friends and realizing that: "The person I trust 'likes' the product," "Everyone is talking about the product" and the like. It is also considered that information-leader types of consumers, who are good at creating topics of conversation, have a greater tendency to make a given product a candidate for purchase. Given the above, this study focused on the ability of the information-leader group to create topics of conversation and revealed how their recognition of a new product and their talk about it actually affected their purchase decision-making. Actual analysis found that a key to a given product being considered more as a candidate for purchase was for the product to be talked about, particularly among consumers who are like information leaders. For a company to introduce a new product and make consumers identify it as a candidate for purchase, it is necessary to implement a communication strategy that starts with the creation of topics of conversation by consumers who are like information leaders and considers how to make them talk about the product.
\end{abstract}

The analysis used the response data related to a brand evaluation included in CANVASS 2011, which was researched by Yomiuri Advertising Company in October 2011. The respondents in this brand evaluation were segmented according to the level of sensitivity to information, into five groups--"nose for news," "open ears," "crowd ears," "empty ears" and "poor hearing"--from the highest to lowest degree of sensitivity to information. This analysis focuses on the two groups--"open ears" and "crowd ears"--from among the five groups. The "open ears" group consists of consumers who are interested in diverse topics, including home, hobbies and health. They are also very interested in society, environment and communities, and they actively absorb various kinds of information and send out summaries. Market mavens belong to this group. The "crowd ears" group is the largest among the five groups and represents a group of average consumers. It was considered appropriate to compare with the "crowd ears" group, which is an average consumer group, in evaluating the condition of the "open ears" group. The new products covered by this analysis comprised 13 brands belonging to six categories: ponzu (ponzu source), cup noodles, yogurt, soda, functional drink and sparkling liquor/new category, all of which were released in March 2010 or later. The analysis used four questions regarding ad recognition (a brand whose ads are seen often), in-store recognition (a brand often seen in stores), topic of conversation (a brand talked about with family, friends, etc.) and consideration (a candidate brand for the next purchase). For each brand, each question was given an answer of " 1 " if the statement was true or an answer of " 0 " if not.

The analysis found the following points: 1)Consumers who are like information leaders, such as those who belong to the "open ears" group, are more likely to talk about a new product as compared to general consumers like those who belong to the "crowd ears" group. 2)Consumers who talk about a new product are more likely to consider the product as compared to consumers who only recognize the product. 3)The likelihood of considering a new product after talking about it increases further in the "open ears" group. These results have the following implications: 1)For a company to introduce a new product and make consumers identify it as a candidate for purchase, it is not sufficient to only implement a communication strategy designed to have consumers recognize the product. 2)Going forward, a communication strategy must be implemented that induces consumers to talk about the product and make it a topic of conversation among consumers. 3)When implementing this strategy, it is necessary to approach consumers who are like information leaders and potential generators of conversation instead of approaching all consumers equally.

References available upon request 